\title{
O TRABALHO COMO PRINCÍPIO EDUCATIVO NA EDUCAÇÃO PROFISSIONAL TÉCNICA DE NÍVEL MÉDIO PARA UMA FORMAÇÃO OMNILATERAL ${ }^{1}$
}

\author{
Cristiane Rodrigues de Freitas ${ }^{2}$ \\ Maria Raimunda Lima Valle ${ }^{3}$ \\ Rosa Oliveira Marins Azevedo ${ }^{4}$ \\ Soraya Farias Aquino 5
}

\section{RESUMO}

O presente artigo tem como objetivo discutir o trabalho como princípio educativo na Educação Profissional Técnica de Nível Médio para a formação omnilateral. Busca, com bases nos dispositivos legais, compreender os reflexos das sucessivas reformas educacionais brasileiras na Educação Profissional e Tecnológica, especificamente, no que se refere à Educação Profissional Técnica de Nível Médio na sua forma de oferta integrada. Reflete a relação trabalho-educação e a concepção do trabalho como princípio educativo, partindo de teóricos que pesquisam a relação existente entre o binômio trabalho-educação. De igual forma, analisa a possibilidade da formação omnilateral como alternativa para superar a formação unilateral que por sua vez reforça a separação entre trabalho manual e trabalho intelectual. Aborda a Educação Profissional Técnica de Nível Médio como o percurso inicial para uma educação não dual. Neste sentido, o itinerário metodológico utilizado no desenvolvimento desse trabalho percorreu o caminho da pesquisa bibliográfica. Como resultado, aponta a necessidade da formação humana integral na perspectiva da formação omnilateral, tomando o trabalho como princípio educativo como caminho inicial no processo de emancipação e autonomia do ser humano.

Palavras-chave: Educação Profissional Técnica de Nível Médio; Formação omnilateral; Trabalho-educação; Trabalho como princípio educativo.

${ }^{1}$ Uma versão preliminar desse texto foi apresentada no I Simpósio Amazônico em Educação Profissional e Tecnológica, promovido pelo ProfEPT/IFAM/CMC, realizado em Manaus, Amazonas, nos dias 28 a 29/11/2018.

${ }^{2}$ Estudante do Mestrado em Educação Profissional e Tecnológica do Instituto Federal de Educação, Ciência e Tecnologia do Amazonas. E-mail: cristianesrr@gmail.com.

${ }^{3}$ Estudante do Mestrado em Educação Profissional e Tecnológica do Instituto Federal de Educação, Ciência e Tecnologia do Amazonas. E-mail: mrlv.bianca@gmail.com.

${ }^{4}$ Doutora em Educação em Ciências e Matemática. Professora do Mestrado em Educação Profissional e Tecnológica do Instituto Federal de Educação, Ciência e Tecnologia do Amazonas. E-mail: marinsrosa@yahoo.com.br.

${ }^{5}$ Doutora em Sociedade e Cultura na Amazônia. Professora do Mestrado em Educação Profissional e Tecnológica do Instituto Federal de Educação, Ciência e Tecnologia do Amazonas. E-mail: soraya.aquino@ifam.edu.br 


\begin{abstract}
This article aims to discuss work as an educational principle in professional technical education at the intermediate level for an omnilateral education. It seeks, based on legal provisions, to understand the reflexes of successive brazilian educational reforms of vocacional and technological education, specifically, regarding the technical professional education of Middle Level in its form of integrated offer. It reflects the relationship between work and education and the conception of work as an educational principle, starting with theorists who research the relationship between the workeducation binomial. In the same way, it analyzes the possibility of the omnilateral formation as an alternative to overcome the unilateral formation that reinforces the separation between manual and intellectual work. It addresses middle-level technical vocational education as the initial course for non-dual education. In this sense, the methodological itinerary used in the development of this work went through the path of bibliographic research. As a result, it points out the necessity of integral human formation in the perspective of omnilateral formation, taking work as an educational principle as the initial path in the process of emancipation and autonomy of the human being.
\end{abstract}

Keywords: Vocational Education Middle Level Technical; Omnilateral Education; Work-Education; Work as an educational principle.

\title{
INTRODUÇÃO
}

O trabalho como princípio educativo vem sendo abordado e defendido por teóricos comoRamos (2008) e Moura (2013), educadores e estudiosos em educação, no Brasil, na perspectiva de uma formação omnilateral ${ }^{6}$, que contrapõe e supera a formação unilateral, característica marcante da sociedade capitalista, presente no sistema de ensino, como também nos demais segmentos formativos da sociedade.Nos debates sobre o tema trabalho-educação, discutidos por Ciavatta (2005), Saviani (2007), Moura, Garcia e Ramos (2007), Neta (2010), entre outros, encontramos a defesa por uma educação básica que tome como princípio educativo a articulação entre o trabalho, a ciência, a cultura e a tecnologia.

Nesses termos, para discutir o trabalho como princípio educativo na Educação Profissional Técnica de Nível Médio - EPTMN para uma formação omnilateral,

\footnotetext{
${ }^{6}$ Formação omnilateral refere-se aquelaeducação que contemplaa formação integral do indivíduo por
} meio da integração das dimensõesdo trabalho, da ciência e da cultura. 
primeiramente, contextualizamos a educação profissional na sua forma de oferta integrada ao ensino médio à luz de suas bases legais oriundas das sucessivas reformas educacionais brasileiras. Em seguida, abordamos, brevemente, os conceitos de trabalho e de educação, buscando articulá-los. Na sequência, fazemos uma reflexão sobre o ensino médio integrado e enfatizamos sobre a necessidade do fomento no espaço escolar da concepção educacional na perspectiva da formação omnilateral.

Em vista de nossa temática, buscamos diálogar com autores que analisam o binômio trabalho-educação, especificamente, com os autores:Saviane (1994, 2007), Ciavatta (2005), Moura, Garcia e Ramos (2007), Ramos (2005, 2008), Neta, Assis e Lima (2008), Araújo e Rodrigues (2010), Borges (2013) e Moura (2013).

Esperamos que as discussões postas, tomando o trabalho como princípio educativo no Ensino Médio Integrado para uma formação omnilateral, possa ser refletido como ponto de partida do processo de emancipação e autonomia do ser humano.

\section{BREVE CONTEXTO E BASES LEGAIS DA EDUCAÇÃO PROFISSIONAL TÉCNICA DE NÍVEL MÉDIO}

Para situarmos a Educação Profissional Técnica de Nível Médio - EPTNM, desde a sua concepção até os seus princípios norteadores, precisamos destacar a Educação Profissional e Tecnológica no contexto educacional brasileiro por meio de suas legislações. Para isto, iniciamos a discussão com a visão de que a Educação Profissional no Brasil, conforme Ramos (2008), sempre foi concebida como um meio de formação imediata, cujo objetivo central é a preparação para o mercado de trabalho, onde os menos favorecidos não possuem outra opção a não ser obter uma profissão para o atendimento das suas necessidades básicas/imediatas. Nesses termos,

Chamamos atenção para o fato de que a razão de ser do ensino médio esteve, ao longo de sua história, predominantemente centrada no mercado de trabalho. Isto de forma imediata, considerando que os seus concluintes procurariam um emprego logo após a conclusão do ensino médio (RAMOS, 2008, p.4).

A Educação Profissional no Brasil iniciou o seu processo de sistematização somente no início do século XX, como destaca Moura (2007, p.6): “O início do século 
XX trouxe uma novidade histórica da educação profissional do país quando houve um esforço público para a organização da formação profissional [...]". No entanto, as leis de educação que surgiram no contexto educacional brasileiro tinham o compromisso com uma formação unilateral em detrimento de uma formação omnilateral, isso favorecia a fragmentação da educação profissional brasileira.

Observamos a formação unilateral citada nas Leis orgânicas da Educação Nacional - a Reforma Capanema,nas leis que institucionalizaram os sistemas $\mathrm{S}$, tendo como exemplo a Lei 4.048/42 que criou o SENAI, até chegarmos na primeira Lei de Diretrizes e Bases da Educação - LDB, a lei 4.024/61, que, conforme Moura (2007), iniciou o seu processo de tramitação no Congresso Nacional em 1948, entrando em vigor somente em 1961; na Lei 5.692/71 "que se constituiu em uma tentativa de estruturar a educação de nível médio brasileiro como sendo profissionalizante para todos." (MOURA, 2007, p.11); no Parecer no 76/1975 que, também, flexibilizou a obrigatoriedade de uma educação profissional para todos, obrigatoriedade que mais tarde foi facultada pela Lei 7.044/82.

Nesta perspectiva, observamos o favorecimento de "novas" teorias pedagógicas que como relatam Araújo e Rodrigues (2010) traziam na sua essência o velho travestido do novo, ou seja, perpetuavam os princípios de uma educação dual que não tinham interesse no indivíduo, sendo o mercado de trabalho o seu foco principal.

As legislações que surgiram no decorrer do século $\mathrm{XX}$ ignoravam a luta dos educadores brasileiros por uma educação igualitária. Essa realidade deu uma "trégua" quando entrou em vigor a Lei de Diretrizes e Bases da Educação 9.394/96, depois de muitas emendas no seu texto original, possibilitando certa abertura para uma possível integração. Mas essa possibilidade foi logo removida por meio do Decreto 2.208/97, que separava a educação profissional da educação "geral", trazendo a oferta dos cursos de educação profissional somente nas formas concomitante e subsequente.

A educação dual brasileira inicia um processo de mudança por meio do Decreto 5.154/2004, que revoga o Decreto 2.208/97, e traz a possibilidade da integração do ensino médio com a educação profissional. Verificamos no documento base da EPTNM, o seguinte sobre o referido decreto:

Esse instrumento legal, além de manter as ofertas dos cursos técnicos concomitantes e subseqüentes trazidas pelo Decreto no. 2.208/97, teve 
o grande mérito de revogá-lo e de trazer de volta a possibilidade de integrar o ensino médio à educação profissional técnica de nível médio, agora, numa perspectiva que não se confunde totalmente com a educação tecnológica ou politécnica, mas que aponta em sua direção porque contém os princípios de sua construção (BRASIL, 2007, p.24).

Em seguida, no cenário legal da EPTNM, destacamos a Lei 11.741/2008 que altera a Lei 9.394/96, no sentido de viabilizar o desenvolvimento de uma Educação Profissional Técnica articulada ao Ensino Médio, podendo ser desenvolvida na forma integrada e concomitante. Especificamente no Artigo 39 da referida lei, destacamos a referência dada à questão da integração na Educação Profissional e Tecnológica EPTpor meio das dimensões do trabalho, da ciência e da tecnologia, observando-se assim, uma "abertura" para o início de um processo de mudanças significativas na formação do indivíduo. Nessa perspectiva, Ramos (2008, p.9) destaca que "Do ponto de vista da política nacional, hoje temos dispositivos legais sobre como construir uma formação integrada no ensino médio com a educação profissional".

Assim, para situarmos a EPTNM na forma integrada, destacamos que a organização da educação profissional e tecnológica abrange a formação inicial e continuada ou qualificação profissional, educação profissional técnica de nível médio EPTNM e de educação profissional tecnológica de graduação e pós-graduação.

Entre os princípios norteadores da EPTNM descritos no Artigo $6^{\circ}$ da Resolução CNE/CEB $n^{\circ}$ 6, de 06/09/2012, destacamos o trabalho como princípio educativo na possibilidade de articulação da educação básica com a educação profissional e tecnológica por meio da formação integral do estudante. As diretrizes curriculares da educação profissional norteam a concepção de educaçãocom ênfase em seu caráter articulador e traz uma proposta de organização curricular que orienta as instituições de ensinoàprática educacional que envolva todos os atores que compõe esse cenário formativo. Sendo assim, a articulação entre o ensino básico e técnico precisair além de um discurso para se tornar uma prática presente e real visandoa formação integral. Esse caminho, deve priorizar aindissociabilidade entre teoria e prática, incorporando o trabalho como princípio educativo (integração entre ciência, tecnologia e cultura) e procurando organizar o seu currículo de forma interdisciplinar, construindo coletivamente um conhecimento que seja significativo para todos. 
Para isso, destacamos que as mudanças trazidas pelas leis vigentes se apresentam como possibilidades viáveis para a construção de um projeto de integração educacional. Contudo, temos consciência de que o conflito dual está presente diariamente em nossa sociedade capitalista, como destaca Neta, Assis e Lima (2016, p.111): "Muito embora a concepção da Educação Profissional - EP tenha passado por modificações, sobretudo no século XX, quando se buscava formar operários para atuarem na incipiente industrialização, ainda permanece o conflito da superação da dualidade".

$\mathrm{Na}$ busca pelo cumprimento de uma educação integrada de nível médio, ressaltamos o parágrafo $7^{\circ}$ da Lei $13.415 / 2017$ que alterou a Lei 9.394/96 e reforça a seguinte concepção de currículo: "Os currículos do ensino médio deverão considerar a formação integral do aluno, de maneira a adotar um trabalho voltado para a construção de seu projeto de vida e para sua formação nos aspectos físicos, cognitivos e socioemocionais".

Dessa forma, a EPTNM na forma integrada seria o início de um caminho para futuras mudanças na educação profissional no país. Conforme Ramos (2008, p. 12), tata-se de uma educação que proporciona, aos sujeitos, a possibilidade de abrirem caminhos e realizarem escolhas para a produção da vida, “[...] uma travessia para uma nova realidade". Nessa mesma direção, Neta, Assis e Lima (2016, p.113) dizem que “A integração é uma condição necessária para a travessia em direção ao ensino médio politécnico e a superação da dualidade educacional pela superação da dualidade das classes".

\section{O TRABALHO COMO PRINCÍPIO EDUCATIVO E A FORMAÇÃo OMNILATERAL NA EPTNM}

A Resolução $n^{\circ}$ 6, de 20/09/2012, a qual define as Diretrizes Curriculares Nacionais para a Educação Profissional Técnica de Nível Médio, ao pormenorizar os princípios da Educação Profissional Técnica de Nível Médio no Art. $6^{\circ}$, entre outros, destaca que o trabalho deve ser assumido como princípio educativo, tendo sua integração com a ciência, a tecnologia e a cultura como base da proposta políticopedagógica e do desenvolvimento curricular. 
À luz das bases legais e de pesquisas brasileiras, procuramos compreender a relação existente entre trabalho e educação: o que se entende, por trabalho como princípio educativo? De igual forma, o que se entende por formação omnilateral? Por que os educadores brasileiros, que se posicionam na defesa de uma educação básica para toda a sociedade com vista na autonomia e emancipação de seus cidadãos, apontam o trabalho como princípio educativo e, principalmente, a formação omnilateral na educação profissional técnica de nível médio?

Para Saviani (2007), trabalho e educação são atividades especificamente humanas, pois apenas o ser humano trabalha e educa. Para Ramos (2008), a dimensão ontológica do trabalho é, também, o ponto de partida para a produção de conhecimentos e de cultura pelos grupos sociais.

Ainda para Ramos (2008), o trabalho é a primeira mediação entre o homem e a realidade material e social. Na sua existência, o homem produz, logo o homem trabalha. O que o homem produz, ele troca, ele vende, logo ele interage com os demais. Desta forma, o homem transforma a natureza e se relaciona com os demais seres de sua própria espécie. O trabalho, portanto, faz parte do homem. O trabalho é a extensão do homem. O fenômeno ontológico do trabalho se manifesta na sua relação indissociável com o homem. Sobre essa lógica, Saviani (2007, p.155) diz que:

Estão aí os fundamentos histórico-ontológicos da relação trabalhoeducação. Fundamentos históricos porque referidos a um processo produzido e desenvolvido ao longo do tempo pela ação dos próprios homens. Fundamentos ontológicos porque o produto dessa ação, o resultado desse processo, é o próprio ser dos homens.

Para Moura, Garcia e Ramos (2007), o ser humano é dotado de múltiplas capacidades que o diferencia e o faz capaz de interagir com os demais seres e com a natureza, sendo capaz de transformar o mundo a partir dos recursos que este lhe proporciona, como o de construir conhecimentos e repassá-los de gerações a gerações. Esse processo de transmissão de conhecimentos adquiridos da prática, advindos das experiências e de soluções de problemas vividos, foi ao longo do tempo convencionado e sistematizado em conceitos e teorias. Esses saberes acumulados, inicialmente, não eram tão elaborados, mas com o passar do tempo e com o avanço das tecnologias em vários campos do saber, surgiu a necessidade de compilá-los, organizá-los, registrá-los e 
ensiná-los de forma sistemática às novas gerações. Para melhor compreensão, Moura, Garcia e Ramos (2007, p. 42) explicam:

[...] homens e mulheres são seres histórico-sociais que atuam no mundo concreto para satisfazerem suas necessidades subjetivas e sociais e, nessa ação, produzem conhecimentos. Assim, a história da humanidade é a história da produção da existência humana e a história do conhecimento é a história do processo de apropriação social dos potenciais da natureza para o próprio homem, mediada pelo trabalho. Por isso, o trabalho é mediação ontológica e histórica na produção de conhecimento.

O homem é um ser do trabalho, pois ontologicamente o trabalho e o homem são simbióticos entre si, ou seja, não dá para separá-los. Nessa perspectiva, acreditamos e tomamos como base os fundamentos que a Formação Humana Integral ou Omnilateral se constitui em uma das categorias principais que sustentam a Educação Profissional Tecnológica. Para Moura, Garcia e Ramos (2007, p.40) essa formação

[...] expressa uma concepção de formação humana, com base na integração de todas as dimensões da vida no processo educativo, visando à formação omnilateral dos sujeitos. Essas dimensões são o trabalho, a ciência e a cultura. O trabalho compreendido como realização humana inerente ao ser (sentido ontológico) e como prática econômica (sentido histórico associado ao modo de produção); a ciência compreendida como os conhecimentos produzidos pela humanidade que possibilita o contraditório avanço das forças produtivas; e a cultura, que corresponde aos valores éticos e estéticos que orientam as normas de conduta de uma sociedade. (MOURA; GARCIA; RAMOS, 2007, p.40).

Os autores supracitados apresentamo trabalho, a ciência e a cultura como expressão da formação omnilateral do ser. Isto implica dizer que o trabalho é a própria expressão do homem e sua relação com a natureza e de onde provém sua sobrevivência. Desta relação homem-trabalho, o ser humano produz ciência e esta se transforma em novas tecnologias. A tecnologia favorece a interação e a comunicação com o outro pela cultura, pela arte, pela dança, por seus costumes, por tudo aquilo que o identifica como pertencente a uma determinada sociedade.

Tomar o trabalho como princípio educativo é considerar o todo do ser humano, é partir do pressuposto de que o trabalho está contido no homem, é considerar o homem na sua essência. Segundo Gramsci (1981, p. 144 apud CIAVATTA, 2005, p. 2), a educação geral deve se tornar parte inseparável da educação profissional em todos os 
campos onde se dá a preparação para o trabalho, dada a necessidade de "[...] enfocar o trabalho como princípio educativo, no sentido de superar a dicotomia trabalho manual/trabalho intelectual, de incorporar a dimensão intelectual ao trabalho produtivo, de formar trabalhadores capazes de atuar como dirigentes e cidadãos".

O Brasil é um país subdesenvolvido e dependente de capital estrangeiro e, considerando as transformações no mundo do trabalho e o processo de desenvolvimento industrial e tecnológico, pode-se observar que a história do sistema educacional brasileiro retrata a marca da dualidade do ensino (SAVIANNI, 2007).

Em outras palavras, o sistema educacional brasileiro, pautado nas sucessivas reformas da educação, apresenta esse modelo dual de formação: uma voltada para a formação geral mais abrangente que prepara melhor os filhos das classes mais favorecidas economicamente com vista ao prosseguimento de estudos universitários; a outra voltada para uma formação específica para o exercício de profissões técnicas que atendam diretamente o mercado de trabalho. Conforme Saviani (2003, p.138): “[...] o ensino profissional é destinado àqueles que devem executar, ao passo que o ensino cientifico-intelectual é destinado àqueles que devem conceber e controlar o processo", sendo aquela diluída ou desprovida de conhecimentos básicos e científicos necessários para a formação integral do homem, o que leva a classe trabalhadora a estagnar seu desenvolvimento e seu potencial criativo, em prol de sua sobrevivência no modo de produção capitalista.

Nesse modelo de produção capitalista, a classe trabalhadora precisa ingressar muito antes no mercado de trabalho. Assim sendo, educadores comprometidos não somente com a formação da classe trabalhadora, mas também com a melhoria das próprias condições detrabalho e existência no mundo, vislumbram uma educação que considere o trabalho, a ciência, a tecnologia e a cultura como princípios fundamentais para uma educação profissional técnica e tecnológica que promova uma formação integral.

A formação integral ou omnilateral, portanto, é aquela que não separa, não divide o que foi construído historicamente pela humanidade, isto é, os conhecimentos advindos do trabalho do homem no mundo, é tranformado e busca satisfazer as necessidades primárias. Essa formação é contrária à unilateralidade, fora do prumo, tortuosa por levar 
em conta somente uma parte ou partes fragmentadas e desconectadas sem considerar a totalidade do ser humano.

A Educação Profissional Técnica de Nível Médio na forma integrada é, portanto, uma alternativa possível de se caminhar nessa direção, especificamente, por acolher jovens que precisam repentinamente tomar decisões, definir rumos de seu percurso formativo.

\section{EDUCAÇÃO PROFISSIONAL TÉCNICA DE NÍVEL MÉDIO: PERSPECTIVAS E PRÁTICAS DE UM NOVO CAMINHO A SER SEGUIDO}

O Ensino Médio Integrado é destacado na perspectiva dos educadores brasileiros como um caminho de transformação da realidade de uma educação dual, perpetuada no Brasil durante décadas; mas para que esse processo se inicie, precisamos começar a organizar, nas instituições que ofertam a EPTNM, a sistematização desse percurso, a fim de não nos perdermos no caminho.

As possibilidades para que um novo contexto educativo comece a emergir nas instituições da EPTNM precisam levar ao fortalecimento de uma prática educativa humanizadora, onde o foco principal deve estar na formação humana integral. Nesse aspecto, Neta, Assis e Lima (2016, p. 108) apontam a necessidade de uma formação que seja de "[...] inclusão social, laboral e política dos sujeitos, numa perspectiva integrada".

Para tanto, a educação profissional e tecnológica deve apropriar-se da visão de formação integradapor meio da construção de um novo conceito dentro das instituições de ensino, a partir de um trabalho coletivo que busque, conforme aponta Ramos (2007), a integração do currículo.

Nesse sentido, para a organização dessa perspectiva humanizadora de formação, faz-se necessário a compreensão do que é o ensino médio integrado, sua importância, objetivo, princípios e as suas possíveis contribuições na EPT. Isso implica na formação docente, pois os docentes contribuirão de forma direta no desenvolvimento de situações formativas no sentido de levar o aluno a ser um profissional pleno e um ser humano integral, participando ativamente na construção de uma formação omnilateral (BORGES, 2013). 
Entendemos essa linha de raciocínio como fundamental para o início dessa travessia de rompimento e superação da educação dual, seguindo para a construção do currículo do EMI e as relações teóricas práticas que promoverão a formação omnilateral, por meio da integração das dimensões trabalho, ciência, cultura e tecnologia.

Diante do entendimento que o currículo integrado agrega dimensões tão abrangentes, enfatizamos que nessa perspectiva de formação, não existe mais a separação ou o enfoque de maior importância de determinado conhecimento em relação ao outro, ou seja, os conhecimentos básicos e específicos na proposta de um currículo integrado passarão por um processo de desfragmentação. Ramos (2005, p.117) destaca que devemos focar em uma perspectiva de discussão sobre "[...] a possibilidade e o desafio de organização do conhecimento num projeto pedagógico que integre trabalho, ciência e cultura nos planos da formação geral e profissional".

Ramos (2005, p.116), ainda destaca que “[...] O currículo integrado organiza o conhecimento e desenvolve o processo de ensino e aprendizagem de forma que os conceitos sejam apreendidos como sistema das relações de uma totalidade concreta que se pretende explicar/compreender".

A discussão de um currículo integrado é vista como possibilidade para fortalecer uma formação articulada, planejada, por meio de um ensino cujo objetivo seja a formação do educando como sujeito pleno, serhistórico, que vivenciará realidades nas quais precisará se posicionar com criticidade e consciência do seu papel social, político e ético dentro da sociedade na qual está inserido. Além disso, deve atuar profissionalmente no mundo do trabalho, pois conforme Neta, Assis e Lima (2016, p.116) “A integração oportunizaria, por meio da organização do trabalho, escolar as transformações sociais capazes de responder às exigências do mundo do trabalho".

Vemos que existem várias situações que precisam ser cuidadosamente consideradas, a fim de que a organização inicial do percurso de uma formação humana integral avance para o alcance dos objetivos tão almejados. Para tanto, concordamos com Moura (2013), quando diz que é necessário o enfrentamento das múltiplas dificuldades que essa concepção educacional enfrenta, devido à realidade política, econômica e social brasileira e destaca que a escola não precisa esperar que as 
transformações ocorram primeiro no modo de produção vigente, já que essa construção deve ser iniciada e vivenciada mesmo em meio às contradições.

Portanto, o desafio da integração na EPTNM pressupõe mudanças, novas possibilidades para a educação e consequentemente para a escola. Portanto, precisamos começar a construção desse percurso, pois "As possibilidades concretas só se configurarão se nos dispusermos a construí-las”. (RAMOS, 2005, p.125).

\section{CONSIDERAÇÕES FINAIS}

Discutimos o trabalho como princípio educativo para uma formação omnilateral, a partir de uma Educação Profissional Técnica de Nível Médio que venha a ser alternativa paramelhorar as condições de desigualdades sociais. Nesse sentido, a construção e sistematização da forma de oferta do Ensino Médio Integrado, por meio de uma perspectiva prática de formação ominilateral, tendo o trabalho como princípio educativo, pode vir a estruturar práticas articuladoras que possibilitem aos discentes e à comunidade escolar se apropriarem de saberes construídos historicamente.

Precisamos partir do princípio que uma educação integrada prioriza a formação do ser na sua totalidade. Por isso, não podemos dissociar e particularizar conhecimentos, pois todos são importantes e devem ser articulados de forma contínua, durante o processo formativo.

Destacamos alguns pontos que consideramos desafiadores na construção de uma formação, na perspectiva omnilateral, são eles:

a) o entendimento de toda a comunidade escolar sobre o que é uma educação integrada, por meio de encontros, oficinas, rodas de conversa, seminários, fóruns, entre outros;

b) a formação docente em Educação Profissional e Tecnológica;

c) o planejamento integrado e participativo;

d) a elaboração de planos de cursos que visem à formação integrada do sujeito;

e) a construção e/ou organização de currículos integrados - partindo do pressuposto que nenhum conhecimento é mais importante que o outro e que currículo não é a junção de conteúdos. 
Assim, o trabalho como princípio educativo precisa ser entendido como parte integrante na construção da EPTNM. Nessa perspectiva, o desafio do Ensino Médio Integrado deve ser lançado à comunidade escolar de forma organizada, a fim de que o foco principal não seja perdido, viabilizando a construção de uma EPTNM dentro das instituições de ensino, tornando-a uma possibilidade real. Além disso, o processo de construção desse caminho, nas instituições educacionais, necessita, em um primeiro momento, de uma reorganização estrutural que possibilite atividades pedagógicas de esclarecimento, formação, análise e discussão de sua organização interna.

A partir dos princípios norteadores da EPTNM, temos as orientações necessárias e legais para promover, dentro das instituições de ensino profissional, uma práticacomprometida com a articulação entre o que é "básico" e "técnico", na perspectiva de uma formação integral que se ancore naindissociabilidade entre teoria e prática. O trabalho como princípio educativo, portanto, deve levar em conta a sua articulação com a ciência, a tecnologia e a cultura, de modo que as instituições responsáveis pela formação profissional devem organizarseus currículos de forma interdisciplinar e coletiva, cujos conhecimentos sejam significativos para todos. 


\section{REFERÊNCIAS}

ARAÚJO, R. M. L.; RODRIGUES, D. S. Referências sobre Práticas Formativas em Educação Profissional: o velho travestido de novo ante o efetivamente novo. Boletim Técnico do Senac, Rio de Janeiro, v.36, n.2, maio/ago. 2010.

BORGES, Maria Célia. Formação de Professores: desafios históricos, políticos e práticos. São Paulo: Paulus, 2013.

BRASIL, Conselho Nacional de Educação. Secretaria de Educação Básica. Diretrizes Curriculares para a Educação Profissional Técnica de Nível Médio. Brasília: MEC, 1999.

Lei de Diretrizes e Bases da Educação Nacional, Lei $\mathbf{n}^{0}$ 11.741/2008. Altera dispositivos da Lei no 9.394/1996, que estabelece as diretrizes e bases da educação nacional.

Lei de Diretrizes e Bases da Educação Nacional. Lei no 9394, de 20 de dezembro de 1996. Brasília, 1996.

MEC. Educação Profissional Técnica de Nível Médio Integrada ao Ensino Médio. Documento base. Brasília, 2007.

Ministério de Educação. Resolução n 06, de 20 de setembro de 2012.

Define Diretrizes Curriculares Nacionais para a Educação Profissional Técnica de Nível Médio. Disponível em:

http://www.portal.mec.gov.br/index.php?option=com_docman\&task=doc_download...

Acesso em: 15 ago. 17.

CIAVATTA, Maria. A Formação Integrada: a escola e o trabalho como lugares de memórias e de identidade. In: RAMOS, Marise (org.).Ensino Médio Integrado: concepções e contradições. São Paulo: Cortez, 2005.

MOURA, Dante Henrique. A Formação de Docentes para a Educação Profissional e Tecnológica. Revista Brasileira da Educação Profissional e Tecnológica, Rio Grande do Norte, v.1, n.1, p.23-38, 2008.

_. Dante Henrique. Educação Básica e Educação Profissional e Tecnológica:dualidade histórica e perspectiva de integração. Holos, Natal, v.2, p.1-27, 2007.

Dante Henrique. Ensino Médio Integrado:subsunção aos interesses do capital ou travessia para a formação humana integral? Revista Educação e Pesquisa, São Paulo, v.39, p.705-720, 2013. 
NETA, Olivia Morais Medeiros; ASSIS, Sandra Maria e LIMA, Aline Cristina Silva. O Trabalho como Princípio Educativo: uma possibilidade de superação da dualidade educacional no ensino médio integrado. Revista Ensino Interdisciplinar, Rio Grande do Norte, v.2, n.05, p. 106-120, 2016.

RAMOS, Marise. Concepção do Ensino Médio Integrado. Disponível em: https://tecnicadmiwj.files.wordpress.com/2008/09/texto-concepcao-do-ensino-mediointegrado-marise-ramos1.pdf. Acesso em: 09 set. 2017.

Marise. Possibilidades e desafios na organização do currículo integrado. In: RAMOS, Marise (Org.).Ensino Médio Integrado: concepções e contradições. São Paulo: Cortez, 2005. P.106-127.

SAVIANI, Dermeval. O trabalho como princípio educativo frente às novas tecnologias. Petrópolis /RJ:Vozes, 1994. 